\title{
SEM Characterization of the Microstructure of Ancient Pueblo Pottery
}

\author{
James H. Steele Jr. Ph.D., 7412 Singing Hills Court, Boulder CO 80301
}

The preparation of porous ceramic materials for characterization via micro-beam techniques can be carried out by impregnating open porosity with a liquid Bi-Sn alloy under pressure, and cooling to solidify the alloy while maintaining applied pressure.[1] Samples mounted using this technique can be mechanically polished without damage or pullouts via standard metallographic procedures that employ diamond pastes for final polishing. Liquid metal fills open porosity and allows argon-ion etching to be applied to remove flowed layers, and to reveal the microstructure of the material constituents. Backscatter electron and cathodoluminescence imaging, and x-ray spectral analyses may then be applied to characterize the microstructure. In many cases imaging and x-ray analyses can be carried out without a conductive coating. Several commercial low melting alloys are available for this type of mounting (e.g., Cerro-alloys based on the binary Bi-Sn eutectic system). These alloys provide several advantages as a mounting material, including expansion of Bi during solidification, which minimizes shrinkage effects and pullouts. Also the eutectic Bi-Sn microstructure increases the hardness of the low melting alloy.

The microstructure of pottery sherds from a pueblo ruin in northern New Mexico near Bandalier National Monument similar to the sherd shown in Figure 1, were examined after filling with liquid Cerrotru , mechanically polishing, and argon ion etching. The sections were examined using backscatter electron imaging with an SEM.

The two micrographs in Figures 2 and 3, show inverted backscatter electron images wherein the porosity exhibits dark contrast, and clay and temper particles are the lighter contrast phases. These micrographs were obtained without coating the mechanically polished and argon-ion etched section. The clay microstructure is interpreted as partially transformed mullite.

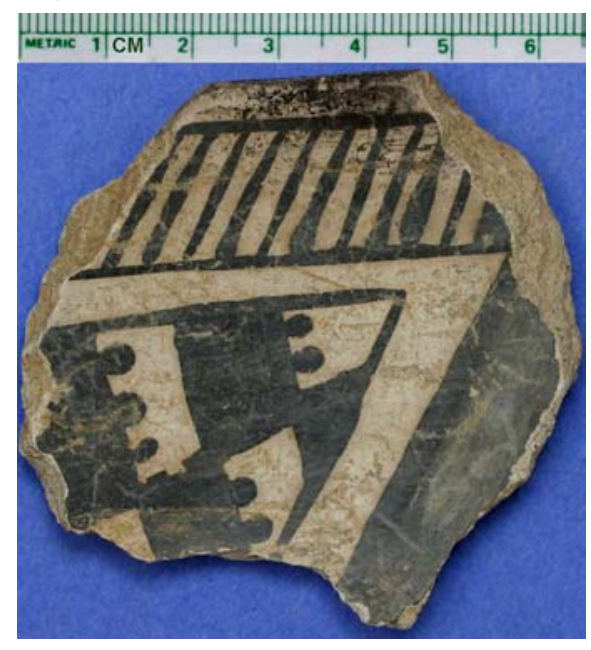

Figure 1 Pottery sherd from Northern NM pueblo ruin. 


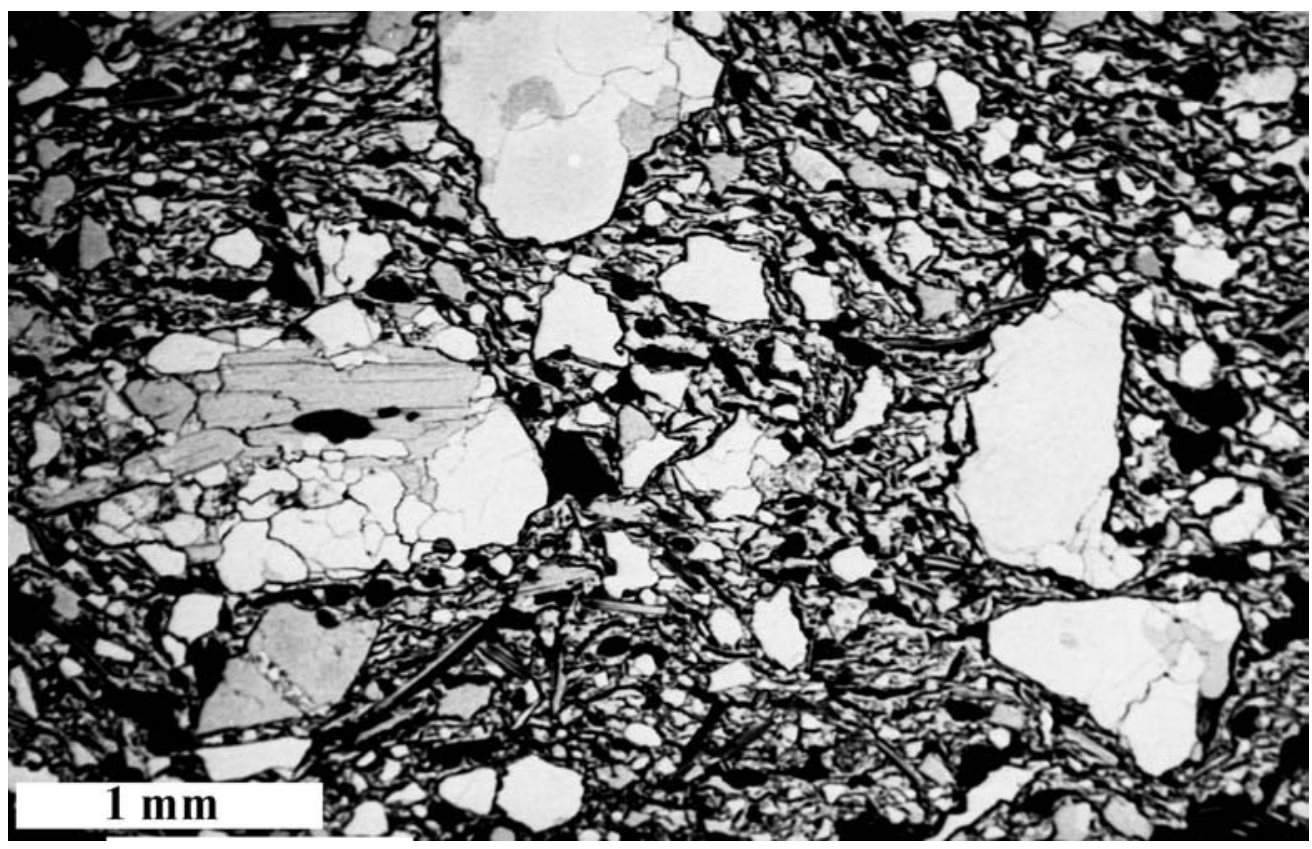

Figure 2 Inverted BSE image of pottery sherd after filling open pores with Bi-Sn alloy and polishing. The gray shades are the result of atomic number contrast.

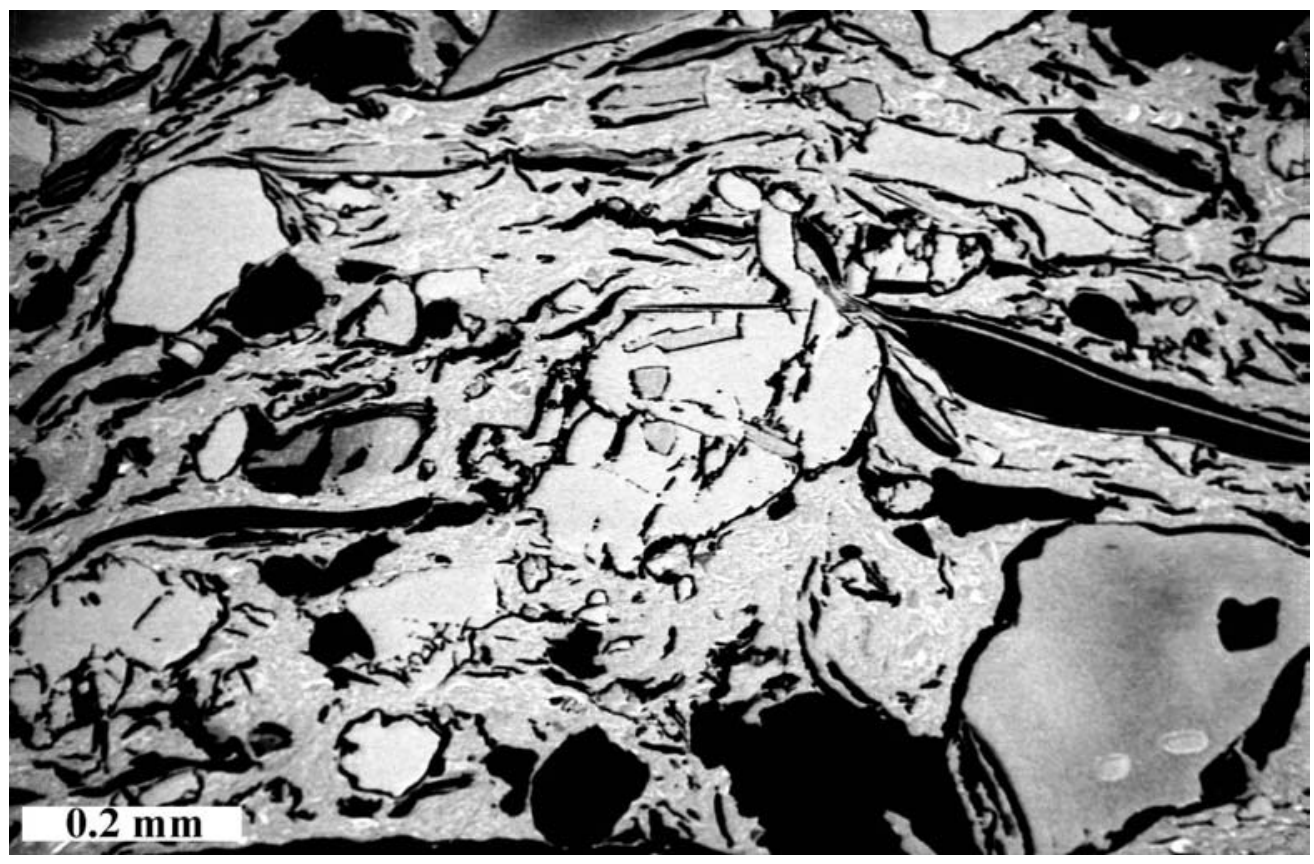

Figure 3 Higher magnification image of the pottery sherd microstructure showing the clay microstructure, which consists of two phases, which is interpreted to result from incomplete transformation to mullite.

[1] J. H. Steele, Microscopy and Microanalysis, Vol. 8, Supp. 2, 2002, p1268CD. 